DOI: $10.1002 /$ ((please add manuscript number))

Article type: Full Paper

\title{
Polymer Main-Chain Substitution Effects on the Efficiency of Nonfullerene BHJ Solar Cells
}

Yuliar Firdaus,,$^{\dagger, \neq}$ Luna P. Maffei,,$^{\dagger \neq}$ Federico Cruciani,,$^{\dagger}$ Michael A. Muller,,$^{\dagger}$ Shengjian Liu,,$^{\dagger}$ Sergei Lopatin,,$^{\S}$ Nimer Wehbe,,$^{\S}$ Guy O. Ngongang Ndjawa, ${ }^{\dagger}$ Aram Amassian, ${ }^{\dagger}$ Frederic Laquai, ${ }^{\dagger}$ and Pierre M. Beaujuge*, ${ }^{*}$

Dr. Y. Firdaus, L. P. Maffei, F. Cruciani, M. A. Muller, Dr. S. Liu, Dr. G. O. N. Ndjawa, Prof. A. Amassian, Prof. F. Laquai and Prof. P. M. Beaujuge King Abdullah University of Science and Technology (KAUST) Physical Sciences and Engineering Division (PSE) KAUST Solar Center (KSC)

Dr. S. Lopatin, Dr. N. Wehbe King Abdullah University of Science and Technology (KAUST) Imaging and Characterization Core Lab Thuwal, 23955-6900, Saudi Arabia E-mail: pierre.beaujuge@kaust.edu.sa

Keywords: polymer solar cells, nonfullerene acceptor, benzo[1,2-b:4,5-b']dithiophene (BDT), organic photovoltaics, 3,4-difluorothiophene, ITIC

\begin{abstract}
"Nonfullerene" acceptors are proving effective in bulk heterojunction (BHJ) solar cells when paired with selected polymer donors. However, the principles that guide the selection of adequate polymer donors for high-efficiency BHJ solar cells with nonfullerene acceptors remain a matter of some debate and, while polymer main-chain substitutions may have a direct influence
\end{abstract}




\section{WILEY-VCH}

on the donor-acceptor interplay, those effects should be examined and correlated with BHJ device performance patterns. This report examines a set of wide-bandgap polymer donor analogues composed of benzo[1,2-b:4,5- $b$ ']dithiophene (BDT), and thienyl $([2 \mathrm{H}] \mathrm{T})$ or 3,4difluorothiophene $([2 \mathrm{~F}] \mathrm{T})$ motifs, and their $\mathrm{BHJ}$ device performance pattern with the nonfullerene acceptor ITIC. Our studies show that the fluorine- and ring-substituted derivative $\operatorname{PBDT}(\mathrm{T})[2 \mathrm{~F}] \mathrm{T}$ largely outperforms its other two polymer donor counterparts, reaching power conversion efficiencies (PCE) as high as 9.8\%. Combining several characterization techniques, the gradual device performance improvements observed on swapping PBDT[2H]T for PBDT[F]T, and then for PBDT(T)[2F]T, are found to result from (i) notably improved charge generation and collection efficiencies (estimated as $c a .60 \%, 80 \%$ and $90 \%$, respectively), and (ii) reduced geminate recombination (being suppressed from $c a$. $30 \%, 25 \%$ to $10 \%$ ) and bimolecular recombination (inferred from recombination rate constant comparisons). Concurrent morphology examinations show comparable and adequate phase separation patterns across the optimized BHJ active layers achieved by blending the wide-bandgap polymer donors PBDT[2X]T and PBDT(T)[2F]T with the nonfullerene acceptor ITIC. These examinations will have broader implications for further studies on the optimization of BHJ solar cell efficiencies with polymer donors and a wider range of nonfullerene acceptors. 


\section{WILEY-VCH}

\section{Introduction}

The extent of progress and fundamental understanding forged in recent years in the development of efficient donor and acceptor materials for polymer solar cells (PSCs) is casting new perspectives in the field. ${ }^{[1-5]}$ While fullerenes, such as phenyl-C61-butyric acid methyl ester ( $\left.\mathrm{PC}_{61} \mathrm{BM}\right)$ or its $\mathrm{C}_{71}$ analogue $\left(\mathrm{PC}_{71} \mathrm{BM}\right)$, have long been the electron-acceptor materials of reference for bulk-heterojunction $(\mathrm{BHJ})$ solar cell studies with polymer and molecular donors, "nonfullerene" alternatives that can absorb in the visible/near-IR spectrum are set out to outperform their fullerene counterparts. ${ }^{[6-17]}$ With reported power conversion efficiencies (PCEs) $>10 \%$, several SM acceptors, including 3,9-bis(2-methylene-(3-(1,1-dicyanomethylene)indanone))-5,5,11,11-tetrakis(4-hexylphenyl)-dithieno[2,3-d:2',3'-d']-s-indaceno[1,2-b:5,6-

b']dithiophene (ITIC), are proving particularly promising with specific polymer donors. ${ }^{[12,17-25]}$ In principle, pairs of polymer donor and SM acceptor with complementary absorption can benefit from their synergistic spectral coverage and yield higher photocurrents than material systems with overlapping absorption. As also implied in a few recent studies, ${ }^{[2,26-27]}$ this primary design rule is however not a sufficient condition, mainly because energetic, morphological and charge transport parameters play determining roles in BHJ solar cells. Considering the prevalent correlations and interdependencies established between polymer main-chain substitution effects and all of the aforementioned parameters in published fullerene-based BHJ device studies, ${ }^{[5,28]}$ the substitution pattern of polymer donors may also influence "nonfullerene" BHJ solar cell 


\section{WILEY-VCH}

efficiencies. In particular, the presence/absence of polar groups, such as fluorine, ${ }^{[29-35]}$ and ringsubstituents ${ }^{[36-40]}$ along the polymer backbone has been shown to significantly impact donor performance in fullerene-based BHJ devices with both polymer and SM donors. ${ }^{[31,35,37,41-43]}$

In this contribution, we report on the comparative efficiencies of a set of analogous, widebandgap polymer donors $\left(E_{\mathrm{opt}} \sim 2.1 \mathrm{eV}\right)$ composed of benzo[1,2-b:4,5-b']dithiophene (BDT), and thienyl $([2 \mathrm{H}] \mathrm{T})$ or 3,4-difluorothiophene $([2 \mathrm{~F}] \mathrm{T})$ motifs, showing distinct performance patterns in BHJ solar cells with the nonfullerene acceptor ITIC. Our detailed device examinations show

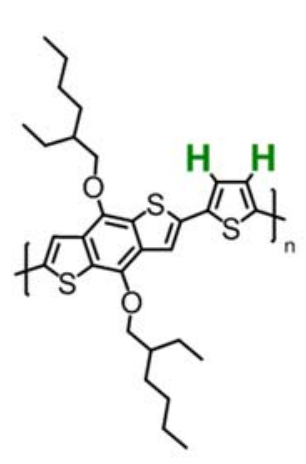

(a) PBDT[2H]T

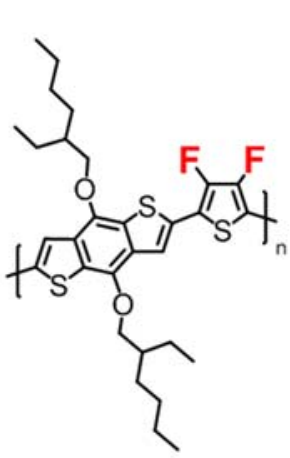

(b) PBDT[2F]T

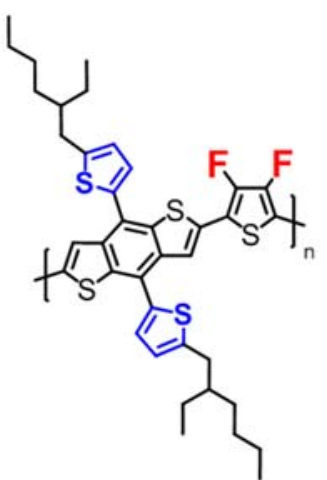

(c) $\operatorname{PBDT}(\mathrm{T})[2 \mathrm{~F}] \mathrm{T}$

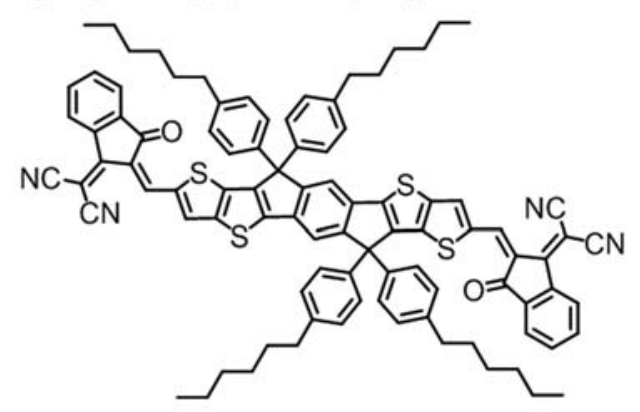

(d) ITIC

Chart 1. Molecular structures of the set of analogous polymer donors (a) PBDT[2H]T, (b) PBDT[2F]T, and (c) PBDT(T)[2F]T, and that of the nonfullerene acceptor (d) ITIC. 


\section{WILEY-VCH}

that the ring-substituted derivative poly(4,8-bis((2-ethylhexyl)oxy)-benzo-[1,2$b: 4, b^{\prime}$ ]dithiophene-3,4-difluoro-thiophene) - namely PBDT(T)[2F]T (Chart 1) - largely outperforms the two other PBDT[2X]T analogues (Chart $1 ; \mathrm{X}=\mathrm{H}$ or F), reaching PCEs as high as 9.8\% (Avg. 9.1\%) in optimized BHJ devices with ITIC. Further comparisons between $\operatorname{PBDT}[2 \mathrm{H}] \mathrm{T}$ and its fluorine(F)-substituted counterparts $\mathrm{PBDT}[2 \mathrm{~F}] \mathrm{T}$ emphasize the critical importance of F-substitutions in the design of efficient polymer donors for non-fullerene BHJ solar cells. We show that the gradual performance improvements observed on swapping PBDT[2H]T for PBDT[2F]T, and then for PBDT(T)[2F]T result from (i) notably improved charge separation and extraction and (ii) reduced geminate and bimolecular recombination across the BHJ active layers.

Surprisingly perhaps, only a handful of polymer donors ${ }^{[18-25,44-45]}$ have been found to perform convincingly well with nonfullerene acceptors to date, and poly(3-hexylthiophene) (P3HT) that has long represented the benchmark in BHJ device examinations with PCBM acceptors, has not proven to perform comparably well with SM acceptors, ${ }^{[7,9,11-13,17]}$ such as ITIC. ${ }^{[22]}$ Since the optical gaps of the nonfullerene ITIC and analogous derivatives tend to be relatively narrow $\left(E_{\mathrm{opt}} \sim 1.6 \mathrm{eV}, \lambda_{\mathrm{abs}}=500-780 \mathrm{~nm}\right)$, wide-bandgap donors - including the PBDT[2X]T polymers $\left(E_{\mathrm{opt}} \sim 2.1 \mathrm{eV}, \lambda_{\mathrm{abs}}=400-600 \mathrm{~nm}\right)$ developed earlier to serve in the high-bandgap subcell of tandem BHJ devices with PCBM acceptors ${ }^{[35]}$ - represent logical candidates for nonfullerene BHJ solar cells with complementary spectral absorption between donor and acceptor components. As with 


\section{WILEY-VCH}

fullerenes, ${ }^{[29-40]}$ inspecting how main-chain substituents impact the development of the BHJ morphologies and device performance may be a critical step to take in the optimization of polymer donor structure relative to specific nonfullerene acceptors. ${ }^{[19,21,23-25]}$

\section{Results and Disscusion}

In this study, all wide-bandgap polymers were prepared following the same Pd-mediated, "Stille-type" cross-coupling polymerization methodology, and were purified using established protocols (cf. details in Supporting Information (SI)). The polymerization methodology afforded batches of comparable MW (cf. SI, Table S1). The thin-film UV-vis optical absorption spectra
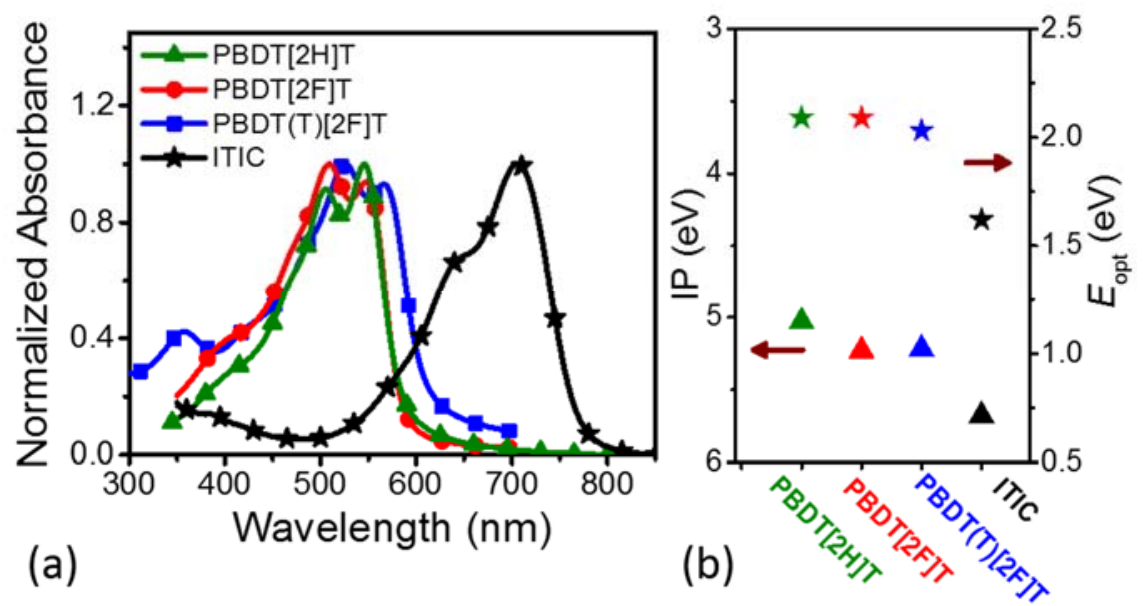

Figure 1. (a) Superimposed, normalized UV-Vis absorbance spectra of the polymer donors (PBDT[2H]T, PBDT[2F]T, PBDT(T)[2F]T) and the small molecule acceptor ITIC (neat films).

(b) PESA-estimated ionization potentials (IP, triangles), optical bandgaps ( $E_{\mathrm{opt}}$, stars) estimated from the onset of the UV-Vis absorption spectra (films) for the three polymer donors and ITIC. 


\section{WILEY-VCH}

(normalized) of PBDT[2H]T, PBDT[2F]T, PBDT(T)[2F]T, and ITIC are superimposed in Figure 1a. All three polymer analogues absorb effectively over the visible-wavelength range 400-600 $\mathrm{nm}$, while ITIC's spectral absorption in the range $500-780 \mathrm{~nm}$ fills in the longer-wavelength region where the donors have only little-to-no absorption. Comparing the onsets of thin-film absorption, a ca. 200-nm bathochromic shift prevails between donor (PBDT[2X]T: $E_{\text {opt }} \sim 2.1 \mathrm{eV}$; $\left.\operatorname{PBDT}(\mathrm{T})[2 \mathrm{~F}] \mathrm{T}: E_{\mathrm{op} r} \sim 2.0 \mathrm{eV}\right)$ and acceptor $\left(E_{\mathrm{op}} \sim 1.59 \mathrm{eV}\right)$ counterparts. Figure $1 \mathrm{~b}$ reports $E_{\mathrm{opt}}$ (stars) and ionization potential (IP) estimates (triangles) pertaining to the polymers and to ITIC; IPs estimated by photoelectron spectroscopy in air (PESA). Expectedly, the IP estimates for $\operatorname{PBDT}(\mathrm{T})[2 \mathrm{~F}] \mathrm{T}(\sim 5.2 \mathrm{eV})$ and PBDT[2F]T $(\sim 5.3 \mathrm{eV})$ are comparably large, and non-negligibly larger than the estimate obtained for their non-fluorinated counterpart PBDT[2H]T $(\sim 5.0 \mathrm{eV}){ }^{[35]}$ Table S1 provides further details, including extrapolated electron affinity (EA) values inferred from estimated IPs and $E_{\text {opt }}$ values.

Thin film BHJ solar cells with the inverted device structure ITO/a-ZnO ${ }^{[46]} /$ Polymer Donor:ITIC/ $\mathrm{MoO}_{3} / \mathrm{Ag}$ (device area: $0.1 \mathrm{~cm}^{2}$ ) were fabricated and tested under AM1.5G solar illumination $\left(100 \mathrm{~mW} / \mathrm{cm}^{2}\right)$. All the films were cast from chlorobenzene (CB) (cf. details in supporting information (SI); film thicknesses in the range 65-80 nm). Systematic device optimization steps included: donor/acceptor (D/A) ratio, use of processing additives, and postprocessing thermal annealing (cf. device statistics provided in the SI, Table S2-S10). Table 1 provides the figures of merit for BHJ solar cells made with the polymer donors PBDT[2H]T, 


\section{WILEY-VCH}

PBDT[2F]T, and PBDT(T)[2F]T, and with ITIC as the nonfullerene acceptor; Figure 2a shows the $J-V$ characteristics of the optimized BHJ devices. As shown in Table 1, nonfullerene BHJ devices made with the wide-bandgap polymer $\mathrm{PBDT}[2 \mathrm{H}] \mathrm{T}$ and subjected to a post-processing thermal annealing step $\left(160^{\circ} \mathrm{C}\right.$, for $10 \mathrm{~min}$ ) can yield PCEs of $2.5 \%$ (Avg. $2.3 \%$ ), albeit with relatively modest $V_{\mathrm{OC}}$ and $F F$ values of $0.79 \mathrm{~V}$ and $41 \%$, respectively. Although modest, it is worth noting that both the $V_{\mathrm{OC}}$ and $J_{\mathrm{SC}}\left(7.6 \mathrm{~mA} / \mathrm{cm}^{2}\right)$ values obtained with PBDT[2H]T are

Table 1. PV Performance of the wide-bandgap polymer donors PBDT[2H]T, PBDT[2F]T and PBDT(T)[2F]T in inverted BHJ devices with the nonfullerene acceptor ITIC; Reference PC $71 \mathrm{BM}$ devices are provided for comparison ${ }^{a}$

\begin{tabular}{|c|c|c|c|c|c|c|c|c|}
\hline Polymer & Acceptor & $\begin{array}{c}\mathrm{D} / \mathrm{A} \\
\text { Ratio }\end{array}$ & An. ${ }^{b} /$ Add. & $\begin{array}{l}\text { Voc } \\
{[V]}\end{array}$ & $\begin{array}{c}\mathrm{J}_{\mathrm{SC}} \\
{\left[\mathrm{mA} / \mathrm{cm}^{2}\right]}\end{array}$ & $\begin{array}{l}\mathrm{FF} \\
{[\%]}\end{array}$ & $\begin{array}{l}\text { Avg. } \\
\text { PCE }^{d} \\
{[\%]}\end{array}$ & $\begin{array}{l}\text { Max. } \\
\text { PCE } \\
{[\%]}\end{array}$ \\
\hline \multirow{2}{*}{ PBDT[2H]T } & \multirow{2}{*}{ ITIC } & \multirow{2}{*}{$5: 5$} & $\mathrm{~N} / \mathrm{N}$ & 0.79 & 6.9 & 39 & 2.0 & 2.1 \\
\hline & & & $\mathrm{Y} / \mathrm{N}$ & 0.79 & 7.6 & 41 & 2.3 & 2.5 \\
\hline \multirow{2}{*}{ PBDT[2F]T } & \multirow{2}{*}{ ITIC } & \multirow{2}{*}{$6: 4$} & $\mathrm{~N} / \mathrm{N}$ & 0.94 & 11.6 & 53 & 5.6 & 5.8 \\
\hline & & & $\mathrm{Y} / \mathrm{N}$ & 0.96 & 10.3 & 55 & 5.3 & 5.4 \\
\hline \multirow{2}{*}{$\operatorname{PBDT}(\mathrm{T})[2 \mathrm{~F}] \mathrm{T}$} & \multirow{2}{*}{ ITIC } & \multirow{2}{*}{$5: 5$} & $\mathrm{~N} / \mathrm{N}$ & 0.96 & 15.5 & 60 & 8.6 & 8.9 \\
\hline & & & $\mathrm{Y} / \mathrm{N}$ & 0.94 & 16.9 & 62 & 9.1 & 9.8 \\
\hline \multirow{2}{*}{$\operatorname{PBDT}(\mathrm{T})[2 \mathrm{~F}] \mathrm{T}$} & \multirow{2}{*}{$\mathrm{PC}_{71} \mathrm{BM}$} & \multirow{2}{*}{$5: 5$} & $\mathrm{Y} / \mathrm{N}$ & 0.86 & 10.4 & 62 & 5.3 & 5.5 \\
\hline & & & $\mathrm{N} / \mathrm{Y}^{c}$ & 0.89 & 10.6 & 69 & 6.3 & $6.5^{e}$ \\
\hline
\end{tabular}

${ }^{a}$ Additional device statistics are provided in the SI (Tables S2-S10). ${ }^{b}$ Thermal annealing: $160{ }^{\circ} \mathrm{C}$, $10 \mathrm{~min}$ for ITIC-based devices; $100{ }^{\circ} \mathrm{C}, 10 \mathrm{~min}$ for PC ${ }_{71} \mathrm{BM}$-based devices. ${ }^{c}$ Devices prepared from blend containing $2.5 \%(\mathrm{v} / \mathrm{v})$ of the processing additive 1-chloronaphthalene $(\mathrm{CN}){ }^{d}$ Average values across $>10$ devices (device area: $0.1 \mathrm{~cm}^{2}$ ). ${ }^{e}$ Device structure: Inverted (cf. details in the SI); PCE values close to those for optimized PBDT[2F]T:PC ${ }_{71} \mathrm{BM}$ BHJ solar cells reported in earlier work (Device structure: Direct; Avg. $\mathrm{PCE}=6.8 \%$ ). ${ }^{[35]}$ 


\section{WILEY-VCH}

significantly higher than those reported thus far for BHJ solar cells made with P3HT and ITIC $\left(V_{\mathrm{OC}}=0.52 \mathrm{~V}, J_{\mathrm{SC}}=4.2 \mathrm{~mA} / \mathrm{cm}^{2}, F F=57 \%\right.$, and $\left.\mathrm{PCE}=1.25 \%\right) .{ }^{[22]}$ Turning to PBDT[2F]T, Table 1 shows that "as-cast" BHJ solar cells made with the F-substituted counterpart PBDT[2F]T yield markedly better figures of merit: $V_{\mathrm{OC}}$ of $0.94 \mathrm{~V}, J_{\mathrm{SC}}$ of $11.6 \mathrm{~mA} / \mathrm{cm}^{2}$, and $F F$ of $53 \%$, resulting in PCEs as high as $5.8 \%$ (Avg. 5.6\%). Interestingly, the twofold efficiency increase reached with PBDT[2F]T is consistence with the doubling of PCE values demonstrated in prior work with the fullerene acceptor PC ${ }_{71} \mathrm{BM}(\mathrm{PBDT}[2 \mathrm{H}] \mathrm{T} \text { : Avg. } \mathrm{PCE}=2.8 \% \text {; PBDT[2F]T: Avg. } \mathrm{PCE}=6.8)^{[35]}-\mathrm{a}$ result that stresses the relevance of the higher-IP (deeper-HOMO) analogue PBDT[2F]T, here increasing the $V_{\mathrm{OC}}$ by $c a .0 .15 \mathrm{eV}$ in nonfullerene BHJ devices with ITIC. In separate work ${ }^{[47]}$ correlating charge transport, quantum-mechanical and molecular dynamics simulations, with solid-state NMR characterizations of the local ordering in thin films of PBDT[2H]T and PBDT[2F]T, the F-substituted counterpart was found to possess a higher propensity for backbone planarity, larger interchain electronic couplings and binding energies between neighboring polymer chains ${ }^{[47]}$ - parameters expected to contribute favorably to the charge transport patterns of wide-bandgap donor in both fullerene ${ }^{[47]}$ and nonfullerene BHJ solar cells.

Considering optimized BHJ devices made with PBDT[2F]T, an evident limiting figure is the $F F$ of $53 \%$. In comparison, polymer-fullerene BHJ solar cells have been shown to yield $F F$ values in the high range $70-80 \%$ in recent years, ${ }^{[35,43,48-49]}$ and achieving comparably high efficiencies with nonfullerene acceptors implies that similarly large $F F$ values be obtained on 


\section{WILEY-VCH}

systematic device optimizations. ${ }^{[50]}$ In PBDTTPD polymers, ${ }^{[36,}$ 51-52] and several other analogues, ${ }^{[53-55]}$ the presence of ring-substituents appended to the polymer main-chain can play determining roles. In particular, in prior work we showed that ring-substituents can mediate the development of the BHJ morphologies that form between polymer donors and PCBM acceptors $^{[36]}$ and, in turn, influence polymer performance in actual BHJ solar cells. Based on those considerations, we set out to examine the influence of thienyl substituents appended to the PBDT[2F]T backbone - the structural modification devised led to the polymer PBDT(T)[2F]T shown in Chart 1. Table 1 lays out the results of our BHJ device optimizations with the widebandgap donor PBDT(T)[2F]T and the nonfullerene acceptor ITIC; reference devices made with the fullerene $\mathrm{PC}_{71} \mathrm{BM}$ are also provided for systematic comparisons.

As shown in Table 1, "as-cast" BHJ solar cells made from PBDT(T)[2F]T and ITIC can yield PCEs as high as $8.9 \%$ (Avg. 8.6\%; further device statistics provided in the SI), combining a Voc of $0.96 \mathrm{~V}$ comparably as large as that of the PBDT[2F]T analogue, and markedly improved $J_{\mathrm{SC}}$ and $F F: 15.5 \mathrm{~mA} / \mathrm{cm}^{2}$ and $60 \%$, respectively. Here, it is also worth noting that the $V \mathrm{oc}$ and $J_{\mathrm{SC}}$ values for $\mathrm{PBDT}(\mathrm{T})[2 \mathrm{~F}] \mathrm{T}$-based devices represent significant improvements over the corresponding figures of merit of the control devices made with the fullerene acceptor $\mathrm{PC}_{71} \mathrm{BM}$ $\left(V_{\mathrm{OC}}=0.86 \mathrm{~V}, J_{\mathrm{SC}}=10.4 \mathrm{~mA} / \mathrm{cm}^{2}\right)$. The spectral absorption of $\mathrm{PC}_{71} \mathrm{BM}$ limited to the shortwavelengths region (where the photon flux is only modest) can explain the substantial difference observed in comparing the $J_{\mathrm{SC}}$ values. As a result, the nonfullerene BHJ solar cells are 


\section{WILEY-VCH}

comparatively more efficient than their fullerene counterparts which yield PCEs of up to $6.5 \%$ (Avg. 6.3\%) upon optimization. While processing additives such as 1,8-diiodooctane (DIO) and 1-chloronaphtalene $(\mathrm{CN})$ - commonly used in the optimization of polymer-PCBM BHJ blend morphologies, ${ }^{[56-58]}$ - did not further improve the figures of merit of BHJ devices made with $\operatorname{PBDT}(\mathrm{T})[2 \mathrm{~F}] \mathrm{T}$ and ITIC (Table S8), a post-processing thermal annealing step $\left(160^{\circ} \mathrm{C}\right.$, for 10 min) helps raise the $F F$ to $62 \%$, leading to BHJ solar cells with PCEs as high as $9.8 \%$ (Avg. 9.1\%; over 30 devices).

The spectral complementarity of ITIC in the long-wavelengths range $(500-780 \mathrm{~nm})$ can be expected to play the determining role in the high $J_{\mathrm{SC}}$ values achieved with the nonfullerene BHJ solar cells. Our transfer matrix simulations (cf. details in the SI, including Figure S2) indicate that a maximum theoretical $J_{\mathrm{SC}}$ of $c a .20 \mathrm{~mA} / \mathrm{cm}^{2}$ for BHJ devices made with ITIC and $\operatorname{PBDT}(\mathrm{T})[2 \mathrm{~F}] \mathrm{T}$ (assuming 100\% IQE; thickness: $75 \mathrm{~nm}$ ) is achievable, while the same simulations performed for devices involving $\mathrm{PC}_{71} \mathrm{BM}$ yield a significantly lower maximum theoretical $J_{\mathrm{SC}}$ of $c a .12 \mathrm{~mA} / \mathrm{cm}^{2}$. In parallel, the calculations shown in Figure $\mathrm{S} 2$ indicate that the maximum theoretical $J_{\mathrm{SC}}$ for PBDT[2H]T- and PBDT[2F]T-based BHJ solar cells is consistent with that for $\mathrm{PBDT}(\mathrm{T})[2 \mathrm{~F}] \mathrm{T}$-based devices, suggesting that all of the three widebandgap, analogous polymers should in principle perform comparably well (cf. further discussions in later sections). 

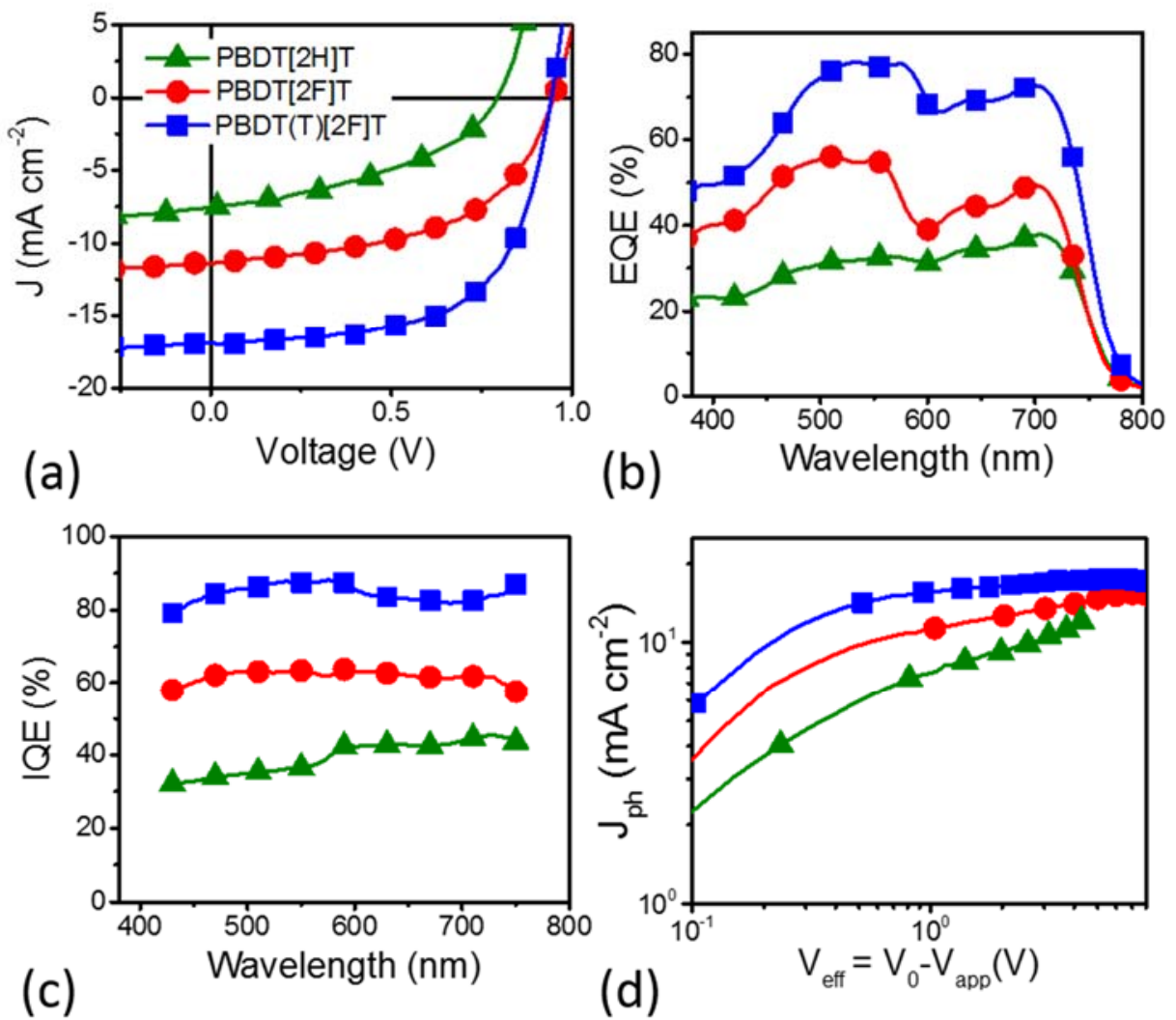

Figure 2. (a) Characteristic $J-V$ curves, (b) EQE spectra, (c) IQE spectra, and (d) $J_{\mathrm{ph}}$ vs. $V_{\text {eff }}$ for optimized BHJ solar cells fabricated from PBDT[2H]T, PBDT[2F]T and PBDT(T)[2F]T, and the SM acceptor ITIC; AM1.5G solar illumination $\left(100 \mathrm{~mW} / \mathrm{cm}^{2}\right)$. Integrated EQEs are in agreement $\left( \pm 0.6 \mathrm{~mA} / \mathrm{cm}^{2} ; \pm 5 \%\right)$ with the $J_{\text {sc }}$ values reported in Table 1 .

The external quantum efficiency (EQE) spectra of optimized BHJ solar cells made from PBDT $[2 \mathrm{H}] \mathrm{T}, \mathrm{PBDT}[2 \mathrm{~F}] \mathrm{T}$ and PBDT(T)[2F]T, and the SM acceptor ITIC, are overlaid in Figure 2b. The trends in $J_{\mathrm{SC}}$ depicted in Figure $2 \mathrm{a}$ are reflected across the EQE spectra, with the higher $J_{\mathrm{SC}}$ values achievable for PBDT(T)[2F]T-based devices $\left(>15 \mathrm{~mA} / \mathrm{cm}^{2}\right)$ paralleling EQEs $>60 \%$ 


\section{WILEY-VCH}

in the range $450-700 \mathrm{~nm}$ and nearing $80 \%$ at the maximum absorption peak of the wide-bandgap polymer PBDT(T)[2F]T (500-560 nm). The EQE spectrum of PBDT[2F]T-based devices follow a similar pattern, albeit at notably lower EQE values ( $<60 \%$ across the visible); in comparison, the EQE spectrum of PBDT[2H]T-based devices falls well below ( $<40 \%$ across the visible). Overall, the spectral complementarity between polymer donors and SM acceptor is however convincingly represented for all donor-acceptor pairs (in agreement with Figure 1a), with balanced EQE contributions from the polymer $(400-600 \mathrm{~nm})$ and from ITIC $(550-780 \mathrm{~nm})$. Integrated photocurrents of $16.4 \mathrm{~mA} / \mathrm{cm}^{2}(\operatorname{PBDT}(\mathrm{T})[2 \mathrm{~F}] \mathrm{T}), 11.1 \mathrm{~mA} / \mathrm{cm}^{2}(\mathrm{PBDT}[2 \mathrm{~F}] \mathrm{T})$ and 7.7 $\mathrm{mA} / \mathrm{cm}^{2}(\mathrm{PBDT}[2 \mathrm{H}] \mathrm{T})$ are in agreement $\left( \pm 0.6 \mathrm{~mA} / \mathrm{cm}^{2} ; \pm 5 \%\right)$ with the $J_{\mathrm{SC}}$ values provided in Table 1 and inferred from the $J-V$ characteristics. Figure 2 c overlays the internal quantum efficiency (IQE) spectra (cf. details on IQE measurements given in the SI), removing the dependence on optical absorption. Noticeably, IQEs of optimized BHJ solar cells made with $\operatorname{PBDT}(\mathrm{T})[2 \mathrm{~F}] \mathrm{T}$ remain $>80 \%$ across the visible spectrum (reaching up to $88 \%$ at $580 \mathrm{~nm}$ ); in comparison, average IQEs for BHJ devices based on PBDT[2H]T and PBDT[2F]T are $c a .61 \%$ and 39\%, respectively. The high IQEs inferred from PBDT(T)[2F]T-based devices suggest that most absorbed photons are conducive to free carrier generation and effective collection at the electrodes, whereas carrier recombination may be at the origin of the substantial IQE losses in PBDT[2X]T-based devices. We also note that the aforementioned average IQEs are in agreement with IQEs estimated from the experimental $J_{\mathrm{SC}}$ divided by the maximum theoretical $J_{\mathrm{SC}}$ 


\section{WILEY-VCH}

calculated by transfer matrix (Table S11) - an observation confirming the accuracy of our optical simulations.

Despite expectations of comparable $J_{\mathrm{SC}}$ values for all three wide-bandgap polymer donors based on the optical model (cf. earlier discussion and Figure S2), PBDT[2X]T-based BHJ solar cells lag behind their counterparts made with $\mathrm{PBDT}(\mathrm{T})[2 \mathrm{~F}] \mathrm{T}$. To evaluate the charge generation and collection losses in BHJ solar cells made from PBDT[2H]T, PBDT[2F]T and $\operatorname{PBDT}(\mathrm{T})[2 \mathrm{~F}] \mathrm{T}$, we analyzed the evolution of photocurrent density $\left(J_{\mathrm{ph}}\right)$ with effective voltage ( $\left.V_{\text {eff }}\right)$ for the optimized BHJ devices; results shown in Figure 2d. Here, $J_{\mathrm{ph}}$ is defined as: $J_{\mathrm{ph}}=J_{\mathrm{L}}$ $J_{\mathrm{D}}$, where $J_{\mathrm{L}}$ and $J_{\mathrm{D}}$ represent the photocurrent densities under light illumination and in the dark, respectively. $V_{\text {eff }}$ is given by: $V_{\text {eff }}=V_{0}-V_{\text {app, }}$, where $V_{0}$ is the compensation voltage when $J_{\mathrm{ph}}=0$ $\mathrm{V}$, and $V_{\text {app }}$ is the applied voltage. ${ }^{[59]}$ The internal electric field in the device is given by $V_{\text {eff }} / L$, where $L$ is the active-layer thickness. ${ }^{[59-60]}$ In PBDT(T)[2F]T-based devices, $J_{\mathrm{ph}}$ increases linearly with increasing $V_{\text {eff }}$ and saturates when $V_{\text {eff }}$ approaches $c a .2 .0 \mathrm{~V}$, indicating that all photogenerated charge carriers are collected when $V_{\text {eff }}>2 \mathrm{~V}$. In parallel, the maximum obtainable photocurrent density $\left(J_{\mathrm{SC}, \max }\right)$ can be calculated based on the optical model (Figure S2, Table S11). The ratio of $J_{\mathrm{sat}}$ to $J_{\mathrm{SC} \text {,max }}$ then provides an estimation of the charge carrier generation efficiency. ${ }^{[61]}$ From these analyses, the $J_{\text {sat }} / J_{\text {SC,max }}$ ratio for PBDT(T)[2F]T-based devices is as high as 0.9 (i.e. $90 \%$ ) and is, in turn, significantly greater than that for the PBDT[2X]T-based devices: $0.75(75 \%)$ and $0.6(60 \%)$ (Table S11), indicating that charge carrier generation is 


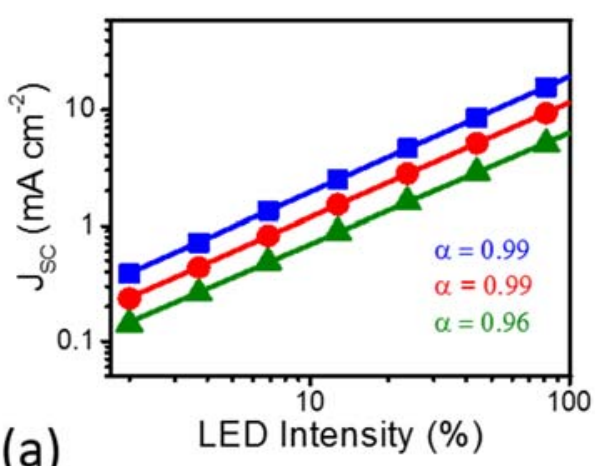

(a)
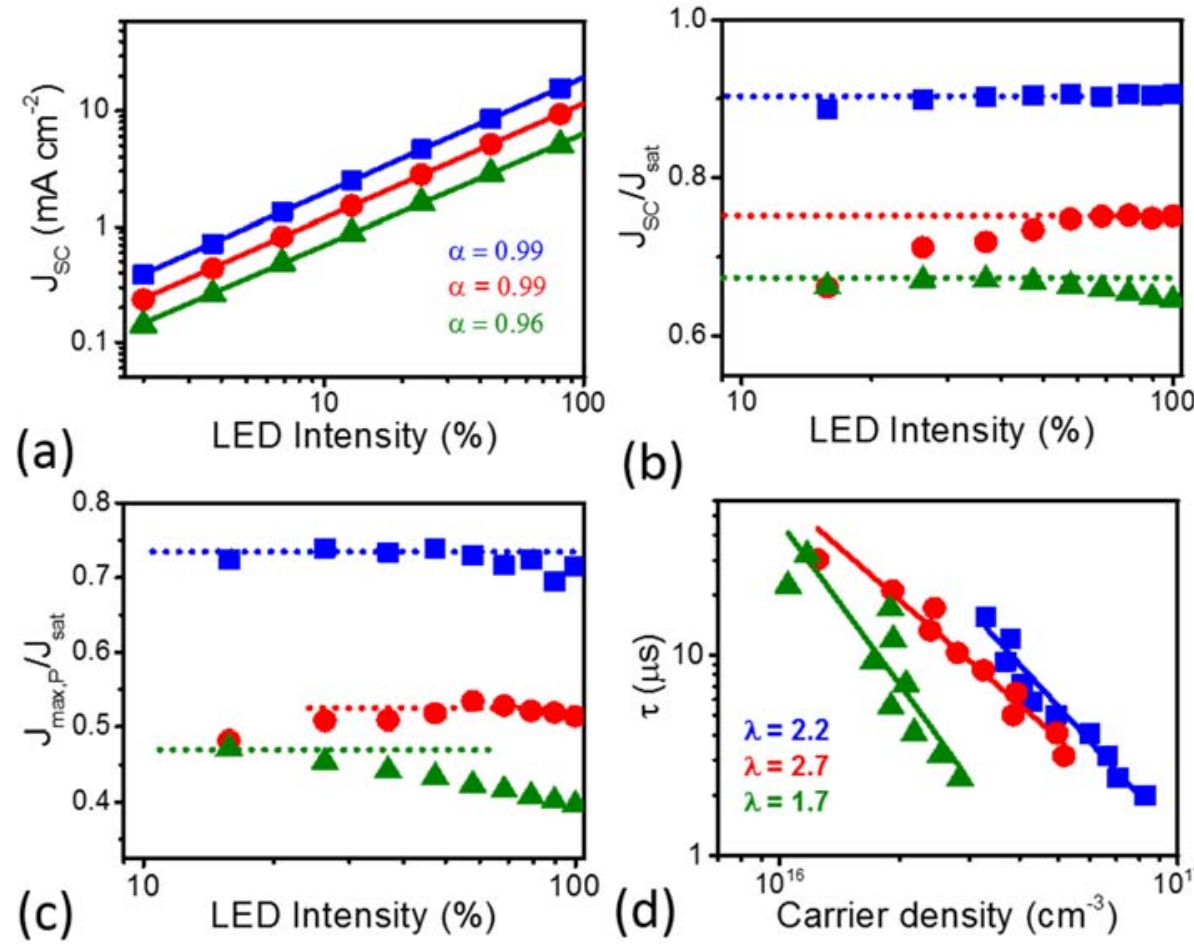

(b)
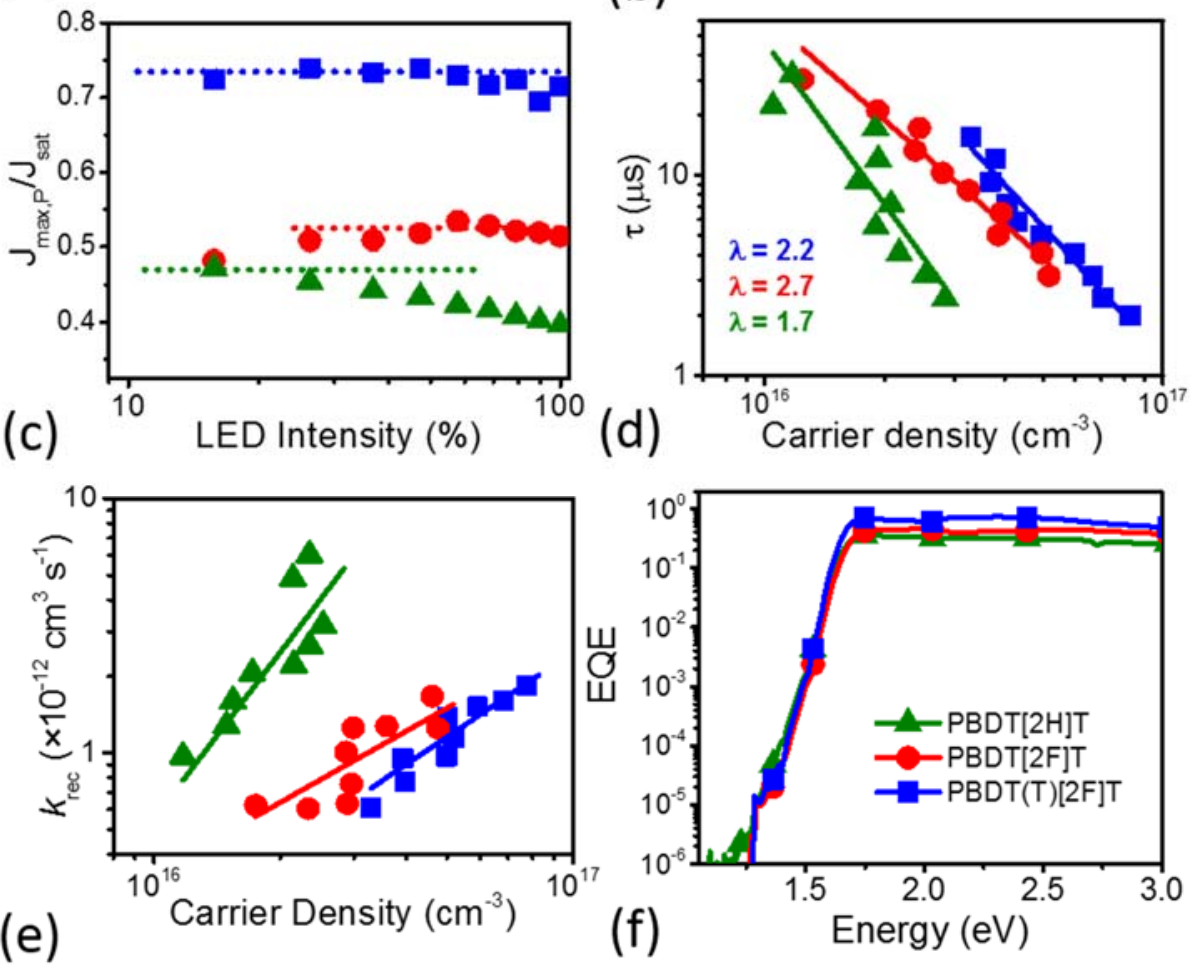

Figure 3. (a) $J_{\mathrm{SC}} v s$. light intensity, (b) $J_{\mathrm{ph}} / J_{\mathrm{sat}} v s$. light intensity at short-circuit, and (c) $J_{\mathrm{ph}} / J_{\mathrm{sat}} v s$. light intensity at the maximum power point. (d) Charge carrier lifetime $\tau$ vs. charge density; carrier densities determined from charge-extraction (CE) measurements (cf. details in the SI). (e)

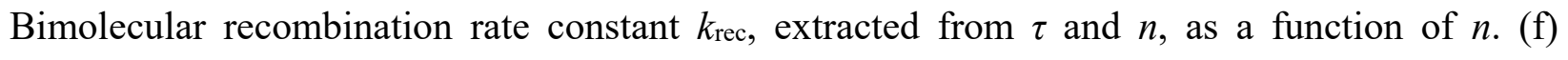
Subgap EQE spectra for optimized BHJ solar cells with the wide-bandgap polymer donors 


\section{WILEY-VCH}

PBDT[2H]T, PBDT[2F]T and PBDT(T)[2F]T, with ITIC as the nonfullerene acceptor. The subgap EQE spectra are shown on a logarithmic scale to highlight the CT bands in the subgap region.

notably more efficient in PBDT(T)[2F]T-based solar cells. From the $J_{\mathrm{ph}} / J_{\text {sat }}$ ratio, the charge transport and collection efficiency at short-circuit ${ }^{[10,22,24,59,61]}$ was estimated to be $c a .90 \%$ (Table S11), indicating that both charge transport and collection processes are very efficient as well. In contrast, the more pronounced dependence of $J_{\text {ph }}$ on $V_{\text {eff }}$ in PBDT[2H]T- and PBDT[2F]T-based devices translates into charge transport and collection efficiencies of less than $60 \%$ and $80 \%$, respectively.

Bimolecular carrier recombination can be characterized via light-intensity dependence measurements, examining $J_{\mathrm{SC}}$ inferred from $J-V$ curves as a function of light intensity (Fig. S4ac) ${ }^{[62]}$ In those experiments, a white-light LED $\left(200 \mathrm{~mW} / \mathrm{cm}^{2}\right.$; spectral mismatch accounted for; cf. experimental details in the SI) is used to reproduce the $J_{\mathrm{SC}}$ values normally obtained under standard AM1.5G solar illumination $\left(100 \mathrm{~mW} / \mathrm{cm}^{2}\right)$. In general, the relationship between $J_{\mathrm{SC}}$ and incident light intensity can be described as: $J_{\mathrm{SC}} \propto \mathrm{I}^{\alpha}$, whereby $\alpha=1$ suggests that all dissociated free carriers are swept out prior to recombination and $\alpha<1$ implies a dependence of $J_{\mathrm{SC}}$ on bimolecular recombination (i.e. most carriers are extracted prior to recombining) ${ }^{[62]}$ Interestingly, from the $J_{\mathrm{SC}}$ vs. light intensity data reported in Figure $3 \mathrm{a}$, the fits yield $\alpha$ values of $0.96,0.99$ and 0.99 for BHJ solar cells made with PBDT[2H]T, PBDT[2F]T and PBDT(T)[2F]T, respectively - 


\section{WILEY-VCH}

suggesting that none of these devices suffer from a significant extent of bimolecular recombination losses under short-circuit conditions. This said, the dependence of $J_{\mathrm{ph}} / J_{\mathrm{sat}}$ on light intensity described in Figure $3 \mathrm{~b}$-c (with $J_{\text {sat }}$ taken as $-3 \mathrm{~V}$ ) conveys the same outcome for optimized PBDT[2F]T- and PBDT(T)[2F]T-based devices under short-circuit conditions (Fig. 3b) and at the maximum power point (Fig. 3c): i.e. bimolecular recombination losses are not apparent considering the relative independence of $J_{\mathrm{ph}} / J_{\mathrm{sat}}$ on device illumination conditions. ${ }^{[61]}$ Therefore, the $10 \%$ photocurrent loss (under short-circuit condition) inferred from prior examinations for PBDT(T)[2F]T-based active layers may arguably stem from geminate recombination processes. ${ }^{[61]}$ The photocurrent losses gradually increase on considering PBDT[2F]T- and PBDT[2H]T-based active layers to over 25\%, suggesting that PBDT[2X]Tbased devices are subject to a greater extent of geminate recombination losses. Also shown in Figure $3 \mathrm{~b}-\mathrm{c}$, the extent of bimolecular recombination in PBDT[2H]T-based devices is nonnegligible. To quantitate the contribution of bimolecular recombination losses (relative to all recombination losses), the $J_{\mathrm{ph}} / J_{\mathrm{sat}}$ ratios are compared at high and low light intensities. In PBDT[2H]T-based active layers, at 100\% light intensity, bimolecular recombination accounts for $4 \%$ and increases to $16 \%$ of all recombination losses at short-circuit (Fig. 3b) and at the maximum power point (Fig. 3c), respectively. In active layers involving PBDT[2F]T and $\operatorname{PBDT}(\mathrm{T})[2 \mathrm{~F}] \mathrm{T}$, at $100 \%$ light intensity, bimolecular recombination accounts for $<3 \%$ and $<1 \%$ 


\section{WILEY-VCH}

of all recombination losses at short-circuit (Fig. 3b) and at the maximum power point (Fig. 3c), respectively.

Further insights into charge recombination across the BHJ active layers can be inferred from transient photovoltage (TPV) measurements ${ }^{[43,63]}$ (cf. decay dynamics in the SI, Figure S5). Carrier lifetimes $(\tau)$ at open-circuit conditions were extracted from the TPV decay dynamics using mono-exponential fits for a wide range of illumination intensities (2-100\% of max. LED intensity), in consistency with prior studies. ${ }^{[43]}$ Figure S5d show that the PBDT[2H]T, PBDT[2F]T and PBDT(T)[2F]T-based active layers- are exhibit similar $\tau$ values $(2 \mu \mathrm{s}-3 \mu \mathrm{s})$ at $81 \%$ of maximum light intensity. Here, we note that, in comparing $\tau$ values, it is important to estimate in parallel the corresponding carrier densities. ${ }^{[43]}$ To this end, charge-extraction (CE) measurements ${ }^{[64]}$ were performed (on the same devices) at various illumination intensities, and the carrier densities $(n)$ obtained from this measurement. Figure $3 \mathrm{~d}$ depicts the evolution of $\tau$ with carrier densities for optimized BHJ solar cells. As shown in Figure 3d, $n$ values increase on going from PBDT[2H]T-, to PBDT[2F]T-, and to PBDT(T)[2F]T-based active layers - a trend in agreement with the relative $J_{\mathrm{SC}}$ values measured for the optimized BHJ solar cells under steady state conditions (Table 1, Figure 2a). The higher $n$ values for PBDT[2F]T- and PBDT(T)[2F]Tbased active layers may stem from a higher exciton dissociation as seen in prior studies. ${ }^{[43]}$ Furthermore, comparable $\tau$ value of PBDT(T)[2F]T and higher $n$ value to that of PBDT[2X]T indicate lower carrier recombination rate in $\operatorname{PBDT}(\mathrm{T})[2 \mathrm{~F}] \mathrm{T}$-based active layer. 


\section{WILEY-VCH}

The bimolecular recombination rate constants $k_{\text {rec }}$ were then inferred from the lifetime values and carrier densities according to $k_{\mathrm{rec}}=1 /(\lambda+1) n \tau,{ }^{[43,63]}$ where $\lambda$ is the recombination order determined from the analyses presented in Figure 3d. As shown in Figure 3e, at all given light intensities, $k_{\text {rec }}$ for the PBDT[2H]T-based devices is larger than those for PBDT[2F]T- and $\operatorname{PBDT}(\mathrm{T})[2 \mathrm{~F}] \mathrm{T}$-based devices. For example, at $81 \%$ of maximum light intensity, $k_{\text {rec }}$ for the PBDT[2H]T-based devices is almost 3 times as large as that for PBDT(T)[2F]T-based BHJ solar cells. Likewise, at all given carrier densities, $k_{\text {rec }}$ for PBDT[2H]T-based active layers is substantially larger than the corresponding values for PBDT[2F]T- and PBDT(T)[2F]T-based active layers (see solid lines in Fig. 3e shown for visual representation purposes). Overall, these results and empirical observations point to significant bimolecular recombination losses in PBDT[2H]T-based BHJ solar cells with ITIC as the acceptor, while these occur to a negligible extent in devices made from PBDT[2F]T and PBDT(T)[2F]T.

The blends of polymer donors and ITIC acceptor having distinct recombination kinetics, the examination of how recombination losses may affect the $V_{\mathrm{OC}}$ of the BHJ solar cells is of interest.

As stated in previous reports referring to the detailed balance theory, ${ }^{[65-67]}$ the difference between $E_{\mathrm{op}} / e$ (where $E_{\mathrm{opt}}$ is inferred from the optical absorption edge, and $e$ is the elementary electric charge) and the experimental $V_{\mathrm{OC}}$ in a BHJ solar cell can be explained from the losses occurring via three main channels. ${ }^{[66]}$ For an ideal solar cell with a step-function absorptance and assuming complete carrier collection, but in the absence of light concentration or any directionality of light 


\section{WILEY-VCH}

emission, one can define an upper limit for the $V_{\mathrm{OC}}$ of a material - knowing $\left(E_{\mathrm{opt}}\right)$ - by using the Shockley-Queisser (SQ) theory according to which the radiative recombination is the only recombination mechanism. ${ }^{[65]}$ For the PBDT[2X]T and PBDT(T)[2F]T-based devices, the corresponding maximum theoretical open-circuit voltage, $V_{\mathrm{OC}, \mathrm{SQ}}$, is ca. $1.3 \mathrm{~V}$ (see Equation $\mathrm{S} 5$ and Table S12 for detailed calculations). Therefore, the first component of the voltage loss inferred from $E_{\mathrm{opt}} / e-V_{\mathrm{OC}, \mathrm{SQ}}$ for the PBDT[2X]T and PBDT(T)[2F]T-based devices is $0.27-0.28$ $\mathrm{eV}$ below $E_{\mathrm{opt}}$; an observation that parallels the ones made for various other systems described in

prior studies. ${ }^{[65-67]}$ A second loss channel: $\Delta V_{\mathrm{OC}, \mathrm{abs}}=V_{\mathrm{OC}, \mathrm{SQ}}-V_{\mathrm{OC}, \text { rad, }}$ stems from the tailing of charge-transfer (CT) states in the bandgap of the $\mathrm{BHJ}$ active layer. The term of radiative voltage

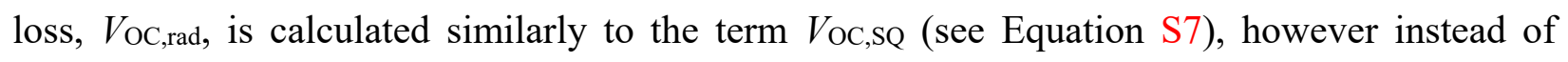
using a step-function like absorptance, the quantum efficiency is measured using sensitive Fourier transform photocurrent spectroscopy (FTPS) as shown in Figure 3f. ${ }^{[67]}$ Our calculations (Table S12) show that $V_{\mathrm{OC}, \text { rad }}$ values are only $0.02-0.09 \mathrm{~V}$ lower than the $V_{\mathrm{OC}, \mathrm{SQ}}$ values stated earlier - estimates in agreement with prior studies addressing nonfullerene BHJ solar cells. ${ }^{[18,67]}$ Last, the third loss channel is linked to non-radiative recombination: $\Delta V_{\mathrm{OC}, \mathrm{nr}}$, depicting the voltage difference between $V_{\mathrm{OC}}$,rad and the measured $V_{\mathrm{OC}}$. This contribution adds a voltage loss of $0.43 \mathrm{~V}$ for PBDT[2H]T-based devices vs. 0.35 and $0.32 \mathrm{~V}$ for PBDT[2F]T- and PBDT(T)[2F]Tbased devices and, in turn, we note that the voltage loss differences across the 


\section{WILEY-VCH}

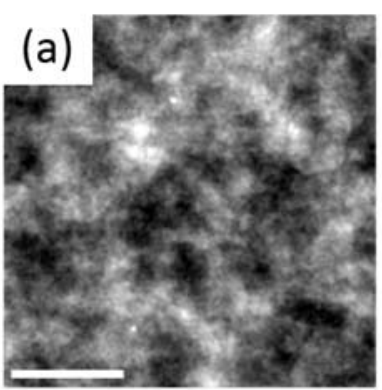

(b)

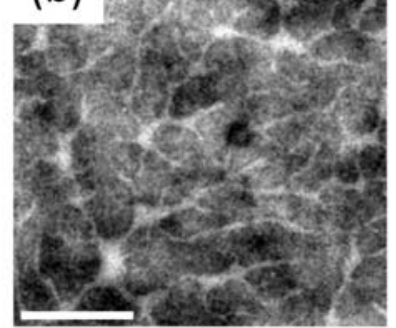

(d)

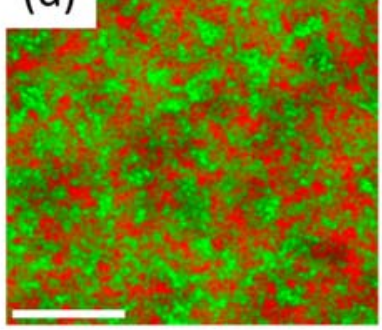

(g)

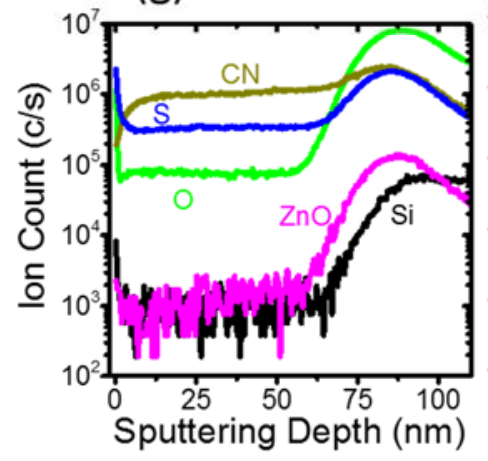

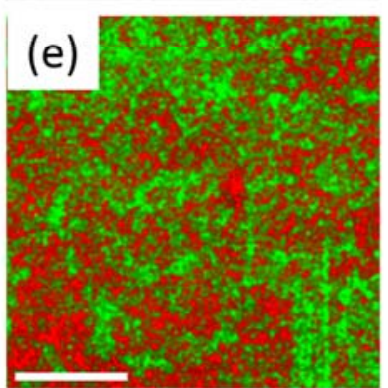

(h)

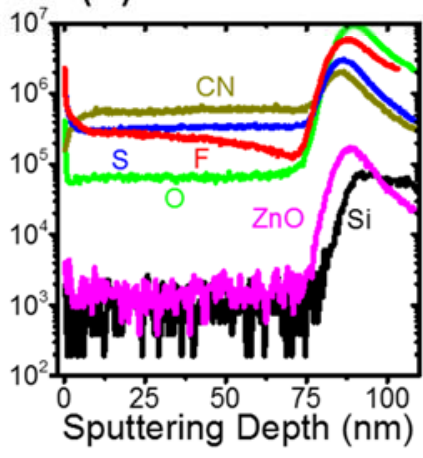

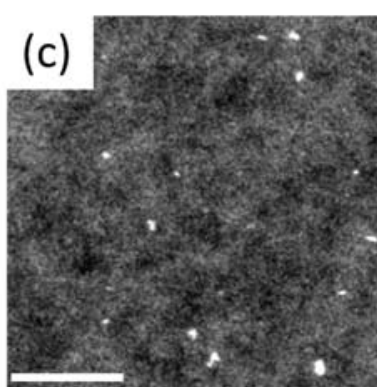

(f)

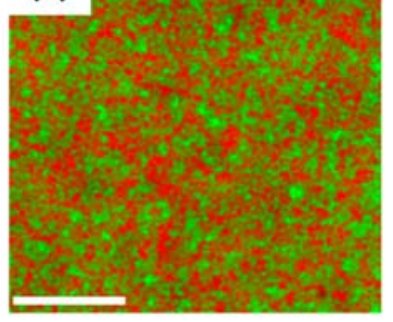

(i)

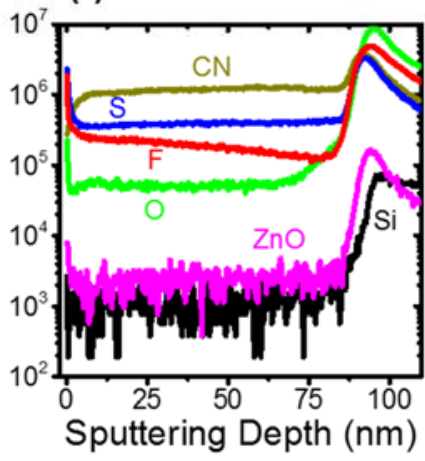

Figure 4. Morphology analyses of ITIC-based BHJ active layers cast with (a,d) PBDT[2H]T, $(\mathbf{b}, \mathbf{e})$ PBDT $[2 F] T$ and (c,f) PBDT(T)[2F]T. (a-c) Dark field STEM images of the optimized BHJ active layers. (d-f) Corresponding EELS maps depicting the phase-separation patterns between polymer donor-rich (red) and nonfullerene acceptor-rich domains (green). Scale bars: $500 \mathrm{~nm}$. (g-i) D-SIMS profiles for the optimized BHJ active layers (cf. details in the SI; active layers cast on a- $\mathrm{ZnO}$-coated $\mathrm{Si}$ ). 


\section{WILEY-VCH}

optimized BHJ solar cells is consistent with the difference in $V$ OC values $(0.15 \mathrm{~V})$ in comparing PBDT[2H]T-based devices vs. PBDT[2F]T- and PBDT(T)[2F]T-based devices (see Table 1).

In polymer-fullerene BHJ solar cells, morphological effects prevail and critically influence carrier transport/recombination patterns and device performance figures. ${ }^{[30,34,36,68]}$ Likewise, in nonfullerene BHJ solar cells, both the length scale and the vertical distribution of donor and acceptor domains may influence device efficiency; ${ }^{[8,50]}$ although, here we note that the number of reports detailing the morphologies of nonfullerene BHJ devices remains limited to date. ${ }^{[7,10-11 \text {, }}$ ${ }^{13,21]}$ Having established fundamental differences in the carrier recombination patterns of active layers with PBDT[2H]T relative to those involving the F-substituted counterparts PBDT[2F] and PBDT(T)[2F]T, we now inspect the BHJ morphologies and possible correlations between the donor-acceptor network and carrier transport/recombination across the active layers. Turning to transmission electron microscopy (TEM) techniques, it should be noted that SM acceptor alternatives to the fullerene PCBM do not typically provide comparable contrast in examining the phase separation of the donor and acceptor components ${ }^{[11,13,22]}$ by transmission (in such films, heterogeneities observed by TEM may also result from the superposition of domains and from film-thickness variations) and, therefore, supporting techniques such as a combination of electron energy-loss spectroscopy (EELS) and scanning TEM (STEM) (Figure 4a,b,c) analyses may prove relevant. In Figures S6g-S8g, the low energy loss region of the EEL spectra for neat films of the polymers and ITIC indicate unique "footprints" associated with inherent differences 


\section{WILEY-VCH}

in inter-band and plasmon electron excitations (cf. details in SI). While scanning the BHJ thin films, these "footprints" can be traced to map out the distribution of polymer donor and ITIC acceptor across the active layers (Figures S6b,c,e,f to S8b,c,e,f). In Figure 4d,e,f, polymer and ITIC maps are superimposed into dual colored images to provide a direct visual representation of the donor-acceptor morphologies (polymer-rich domains: red; ITIC-rich domains: green). As shown in Figure 4d-f, a phase-separated network of donor- and acceptor-rich domains exists for all three optimized BHJ active layers cast with ITIC. Here, the BHJ morphologies of the optimized devices appear comparably well mixed, and no clear difference in phase separation patterns can be observed at the scale of those analyses. These observations are in agreement with the photoluminescence (PL) quenching efficiency data for BHJ thin-films shown in Figure S9, with $>86 \%$ PL quenching efficiency when probing the PL of ITIC-rich domains and $>95 \%$ PL quenching when probing the PL of polymer-rich domains of the blend films (cf. details in the SI).

The vertical phase distribution of donor and acceptor counterparts across the active layer has been demonstrated to further impact BHJ solar cell performance for polymer-fullerene blends. ${ }^{[69]}$ To examine those effects in the nonfullerene BHJ thin films cast with PBDT[2H]T, PBDT[2F]T and $\operatorname{PBDT}(\mathrm{T})[2 \mathrm{~F}] \mathrm{T}$, we turned to an analysis of the thin films' depth profiles via dynamic secondary-ion mass spectrometry (D-SIMS). Figure 4g-i shows the D-SIMS depth profiles of the optimized BHJ active layers with ITIC (blend films cast on a-ZnO-coated Si; cf. experimental details in the SI). Looking at the BHJ thin films based on the F-substituted polymers PBDT[2F]T 


\section{WILEY-VCH}

and $\operatorname{PBDT}(\mathrm{T})[2 \mathrm{~F}] \mathrm{T}$, the traces associated with $\mathrm{F}$-atomic contents indicate a gradual concentration increase in polymer on going from the a- $\mathrm{ZnO}$ interface (right hand) to the top of the active layer (left hand). This trend is paralleled by a gradual concentration increase in detected -CN groups (end groups in ITIC) on going from the top of the active layer (left hand) to the a- $\mathrm{ZnO}$ interface (right hand). These inversed, consistent trends in polymer donor and ITIC density gradients across the active layers follow a favorable pattern: ITIC present in higher concentrations towards the a- $\mathrm{ZnO}$ cathode interface where electrons are extracted, while a polymer accumulation towards the anode can promote hole extraction. ${ }^{[69-71]}$ Looking at the BHJs based on the PBDT[2H]T analogue and the trace pertaining to the $-\mathrm{CN}$ groups (reflecting ITIC contents), a similar trend can be observed: gradual concentration increase on going from the top of the active layer (left hand) to the a-ZnO interface (right hand); although here, the detected $\mathrm{F}$ atomic content is expectedly negligible.

Overall, the BHJ blend morphologies formed by all three wide-bandgap polymer donors and the nonfullerene ITIC appear adequate, and inverted device structures are chosen appropriately in light of the vertical distribution of donor and acceptor counterparts across the BHJ active layers (in agreement with our device optimizations, direct vs. inverted, presented in Table S4 and S5). In turn, thin film morphologies being "comparable" at the level of our analyses, other influencing factors such as (i) the purity of the donor- and acceptor-rich phases, ${ }^{[8,72]}$ and (ii) the local arrangement and electronic structure at the donor-acceptor interfaces, ${ }^{[73-74]}$ may be at play. 


\section{WILEY-VCH}

Aside from donor/acceptor phase-separation considerations, polymer main-chain substituents impact local ordering ${ }^{[36,47]}$ and can promote the propensity for backbone planarity, inducing larger interchain electronic couplings and binding energies between neighboring polymer chains. ${ }^{[47]}$ Since such parameters are expected to contribute favorably to the charge transport patterns of wide-bandgap polymer donors in both fullerene $\mathrm{e}^{[47]}$ and nonfullerene BHJ solar cells, we turned to MIS-CELIV measurements (MIS: Metal-Insulator-Semiconductor, CELIV: Charge Extraction by Linearly Increasing Voltage $)^{[75-76]}$ for a systematic analyses of the carrier mobilities in the polymer neat films, and in optimized BHJ active layers made with PBDT[2H]T, PBDT[2F]T and PBDT(T)[2F]T, and the acceptor ITIC (cf. experimental details and results provided in the SI, Figures S10 and Tables S13). As shown in Table S13, MIS-CELIV-inferred hole mobility estimates for neat films of PBDT[2F]T films are $c a .4 \times$ greater than those for neat films of the PBDT[2H]T analogue: $9.2 \times 10^{-6} \mathrm{~cm}^{2} \mathrm{~V}^{-1} \mathrm{~s}^{-1}$ vs. $2.2 \times 10^{-6} \mathrm{~cm}^{2} \mathrm{~V}^{-1} \mathrm{~s}^{-1}$, respectively; results in close agreement with space-charge-limited current (SCLC) values estimated in earlier work. ${ }^{[47]}$ In parallel, MIS-CELIV mobility estimates for neat films of the ring-substituted counterpart PBDT(T)[2F]T: 7.6 $\times 10^{-5} \mathrm{~cm}^{2} \mathrm{~V}^{-1} \mathrm{~s}^{-1}$ (Figure S10, Table S13), are over one order of magnitude greater than those for PBDT[2H]T, and also $c a .8 \times$ as high as those for PBDT[2F]T suggesting that $\mathrm{BDT}(\mathrm{T})$ motifs in $\mathrm{PBDT}(\mathrm{T})[2 \mathrm{~F}] \mathrm{T}$ are playing a role in local ordering and interchain electronic couplings. ${ }^{[47]}$ In optimized BHJ active layers, our MIS-CELIV analyses show that the overall trend in hole mobilities is retained on considering films made with 


\section{WILEY-VCH}

PBDT[2H]T, PBDT[2F]T and PBDT(T)[2F]T: $5.7 \times 10^{-6} \mathrm{~cm}^{2} \mathrm{~V}^{-1} \mathrm{~s}^{-1}, 1.5 \times 10^{-5} \mathrm{~cm}^{2} \mathrm{~V}^{-1} \mathrm{~s}^{-1}$ and $3 \times$ $10^{-5} \mathrm{~cm}^{2} \mathrm{~V}^{-1} \mathrm{~s}^{-1}$, respectively (Figure $\mathrm{S} 11$, Table $\mathrm{S} 13$ ). Thus, hole mobility estimates for PBDT(T)[2F]T:ITIC active layers are $c a .2 \times$ as high as those for PBDT[2F]T:ITIC, and $c a .5 \times$ greater than those for PBDT[2H]T:ITIC. Interestingly, as also shown in Table S13, electron mobilities fall within the same order of magnitude for all three optimized BHJ active layers with the acceptor ITIC; in PBDT[2H]T-, PBDT[2F]T- and PBDT(T)[2F]T-based devices: $2.2 \times 10^{-5}$ $\mathrm{cm}^{2} \mathrm{~V}^{-1} \mathrm{~s}^{-1}, 1.0 \times 10^{-5} \mathrm{~cm}^{2} \mathrm{~V}^{-1} \mathrm{~s}^{-1}$ and $1.2 \times 10^{-5} \mathrm{~cm}^{2} \mathrm{~V}^{-1} \mathrm{~s}^{-1}$, respectively (Figure $\mathrm{S} 11$, Table $\mathrm{S} 13$ ) These results stress the critical influence of polymer main-chain substitution effects on hole transport in nonfullerene BHJ solar cells.

\section{Conclusion}

In summary, we showed that - from a set of analogous, wide-bandgap polymer donors $\left(E_{\mathrm{op} \sim} \sim 2.1 \mathrm{eV}\right):$ PBDT[2H]T, PBDT[2F]T and PBDT(T)[2F]T (Chart 1$)-$ the selection of polymer main-chain substituents has a critical impact on the performance of BHJ solar cells with the nonfullerene acceptor ITIC. Specifically, our detailed device studies show that the fluorine- and ring-substituted derivative $\mathrm{PBDT}(\mathrm{T})[2 \mathrm{~F}] \mathrm{T}$ largely outperforms the two analogous $\mathrm{PBDT}[2 \mathrm{X}] \mathrm{T}$ counterparts $(\mathrm{X}=\mathrm{H}$ or $\mathrm{F})$, reaching PCEs as high as 9.8\% (Avg. 9.1\%) in optimized BHJ devices. The combination of characterization techniques used indicate that the gradual performance improvements observed on swapping PBDT[2H]T for PBDT[2F]T, and then for PBDT(T)[2F]T, result from (i) notably improved charge generation and collection efficiency (estimated as $c a$. 


\section{WILEY-VCH}

$60 \%, 80 \%$ and $90 \%$, respectively) and (ii) reduced geminate recombination (loss inferred from the photocurrent at short-circuit and the saturation current as ca. $30 \%, 25 \%$ to $10 \%$ ) and bimolecular recombination (seen from the lower recombination rate constant $k_{\text {rec, }}$ which is three times lower for PBDT(T)[2F]T-based devices than that of PBDT[2H]T-based devices at $81 \%$ of maximum light intensity), across the BHJ active layer of PBDT(T)[2F]T-based devices. Morphology correlations by EELS-TEM and D-SIMS suggest comparable phase-separation patterns across optimized BHJ solar cells - pointing to the idea that recombination losses may be inherent to (i) the purity of the donor- and acceptor-rich phases, ${ }^{[8,}{ }^{72]}$ and (ii) the local arrangement and electronic structure at the donor-acceptor interfaces ${ }^{[73-74]}$. Those are equally important aspects for further studies on the optimization of BHJ device efficiencies with PBDT(T)[2F]T and a wider range of nonfullerene acceptors.

\section{Supporting Information}

Experimental methods, characterization, and additional figures and tables. Supporting Information is available from the Wiley Online Library or from the authors.

\section{Acknowledgements}

This publication is based upon work supported by the King Abdullah University of Science and Technology (KAUST) Office of Sponsored Research (OSR) under Award No. CRG_R2_13_BEAU_KAUST_1. The authors acknowledge concurrent support under Baseline Research Funding from KAUST. The authors thank KAUST ACL for technical support in the 


\section{WILEY-VCH}

mass spectrometry analyses, GPC and elemental analyses. The authors thank Z. Kan and M.

Babics for the discussions in device characterizations. Y. Firdaus and L. P. Maffei contributed equally to this work.

Received: ((will be filled in by the editorial staff))

Revised: ((will be filled in by the editorial staff)) Published online: ((will be filled in by the editorial staff))

\section{References:}

[1] I. Etxebarria, J. Ajuria, R. Pacios, Org. Electron. 2015, 19, 34.

[2] L. Y. Lu, T. Y. Zheng, Q. H. Wu, A. M. Schneider, D. L. Zhao, L. P. Yu, Chem. Rev. 2015, 115, 12666.

[3] J. F. Yan, B. R. Saunders, RSC. Adv. 2014, 4, 43286.

[4] F. L. Zhang, O. Inganas, Y. H. Zhou, K. Vandewal, Natl. Sci. Rev. 2016, 3, 222.

[5] P. M. Beaujuge, J. M. J. Frechet, J. Am. Chem. Soc. 2011, 133, 20009.

[6] S. Holliday, R. S. Ashraf, A. Wadsworth, D. Baran, S. A. Yousaf, C. B. Nielsen, C. H. Tan, S. D. Dimitrov, Z. R. Shang, N. Gasparini, M. Alamoudi, F. Laquai, C. J. Brabec, A. Salleo, J. R. Durrant, I. McCulloch, Nat. Commun. 2016, 7, 11585.

[7] Y. Z. Lin, J. Y. Wang, Z. G. Zhang, H. T. Bai, Y. F. Li, D. B. Zhu, X. W. Zhan, Adv. Mater. 2015, 27, 1170.

[8] Y. Z. Lin, F. W. Zhao, Q. He, L. J. Huo, Y. Wu, T. C. Parker, W. Ma, Y. M. Sun, C. R. Wang, D. B. Zhu, A. J. Heeger, S. R. Marder, X. W. Zhan, J. Am. Chem. Soc. 2016, 138, 4955.

[9] F. Liu, Z. C. Zhou, C. Zhang, T. Vergote, H. J. Fan, F. Liu, X. Z. Zhu, J. Am. Chem. Soc. 2016, $138,15523$.

[10] D. Sun, D. Meng, Y. H. Cai, B. B. Fan, Y. Li, W. Jiang, L. J. Huo, Y. M. Sun, Z. H. Wang, J. Am. Chem. Soc. 2015, 137, 11156. 


\section{WILEY-VCH}

[11] K. Wang, Y. Firdaus, M. Babics, F. Cruciani, Q. Saleem, A. El Labban, M. A. Alamoudi, T. Marszalek, W. Pisula, F. Laquai, P. M. Beaujuge, Chem. Mater. 2016, 28, 2200.

[12] Y. K. Yang, Z. G. Zhang, H. J. Bin, S. S. Chen, L. Gao, L. W. Xue, C. Yang, Y. F. Li, J. Am. Chem. Soc. 2016, 138, 15011.

[13] H. F. Yao, Y. Chen, Y. P. Qin, R. N. Yu, Y. Cui, B. Yang, S. S. Li, K. Zhang, J. H. Hou, Adv. Mater. 2016, 28, 8283.

[14] L. Ye, K. Sun, W. Jiang, S. Q. Zhang, W. C. Zhao, H. F. Yao, Z. H. Wang, J. H. Hou, ACS Appl. Mater. Interfaces 2015, 7, 9274.

[15] J. D. Yi, Y. L. Wang, Q. Luo, Y. Lin, H. W. Tan, H. Y. Wang, C. Q. Ma, Chem. Commun. 2016, 52, 1649.

[16] Y. Zhong, M. T. Trinh, R. S. Chen, G. E. Purdum, P. P. Khlyabich, M. Sezen, S. Oh, H. M. Zhu, B. Fowler, B. Y. Zhang, W. Wang, C. Y. Nam, M. Y. Sfeir, C. T. Black, M. L. Steigerwald, Y. L. Loo, F. Ng, X. Y. Zhu, C. Nuckolls, Nat. Commun. 2015, 6, 8242.

[17] S. Li, L. Ye, W. Zhao, S. Zhang, S. Mukherjee, H. Ade, J. Hou, Adv. Mater. 2016, 28, 9423.

[18] W. C. Zhao, D. P. Qian, S. Q. Zhang, S. S. Li, O. Inganas, F. Gao, J. H. Hou, Adv. Mater. 2016, $28,4734$.

[19] Z. K. Li, K. Jiang, G. F. Yang, J. Y. L. Lai, T. X. Ma, J. B. Zhao, W. Ma, H. Yan, Nat. Commun. 2016, 7, 13094.

[20] H. J. Bin, L. Gao, Z. G. Zhang, Y. K. Yang, Y. D. Zhang, C. F. Zhang, S. S. Chen, L. W. Xue, C. Yang, M. Xiao, Y. F. Li, Nat. Commun. 2016, 7, 13651.

[21] Z. Zheng, O. M. Awartani, B. Gautam, D. Liu, Y. Qin, W. Li, A. Bataller, K. Gundogdu, H. Ade, J. Hou, Adv. Mater. 2016, 29, 1604241.

[22] Y. Qin, M. A. Uddin, Y. Chen, B. Jang, K. Zhao, Z. Zheng, R. Yu, T. J. Shin, H. Y. Woo, J. Hou, Adv. Mater. 2016, 28, 9416. 


\section{WILEY-VCH}

[23] J. Yuan, L. X. Qiu, Z. G. Zhang, Y. F. Li, Y. W. Chen, Y. P. Zou, Nano Energy 2016, 30, 312.

[24] L. Gao, Z.-G. Zhang, H. Bin, L. Xue, Y. Yang, C. Wang, F. Liu, T. P. Russell, Y. Li, Adv. Mater. 2016, 28, 8288.

[25] H. J. Bin, Z. G. Zhang, L. Gao, S. S. Chen, L. Zhong, L. W. Xue, C. Yang, Y. F. Li, J. Am. Chem. Soc. 2016, 138, 4657.

[26] C. Poelking, D. Andrienko, J. Am. Chem. Soc. 2015, 137, 6320.

[27] C. L. Zhan, J. N. Yao, Chem. Mater. 2016, 28, 1948.

[28] H. X. Zhou, L. Q. Yang, W. You, Macromolecules 2012, 45, 607.

[29] J. Kim, M. H. Yun, G. H. Kim, J. Lee, S. M. Lee, S. J. Ko, Y. Kim, G. K. Dutta, M. Moon, S. Y. Park, D. S. Kim, J. Y. Kim, C. Yang, ACS Appl. Mater. Interfaces 2014, 6, 7523.

[30] A. C. Stuart, J. R. Tumbleston, H. X. Zhou, W. T. Li, S. B. Liu, H. Ade, W. You, J. Am. Chem. Soc. 2013, 135, 1806.

[31] J. W. Jo, S. Bae, F. Liu, T. P. Russell, W. H. Jo, Adv. Funct. Mater. 2015, 25, 120.

[32] H. J. Son, W. Wang, T. Xu, Y. Y. Liang, Y. E. Wu, G. Li, L. P. Yu, J. Am. Chem. Soc. 2011, 133, 1885.

[33] W. T. Li, S. Abrecht, L. Q. Yang, S. Roland, J. R. Tumbleston, T. McAfee, L. Yan, M. A. Kelly, H. Ade, D. Neher, W. You, J. Am. Chem. Soc. 2014, 136, 15566.

[34] S. Guo, J. Ning, V. Korstgens, Y. Yao, E. M. Herzig, S. V. Roth, P. Muller-Buschbaum, Adv. Energy Mater. 2015, 5, 1401315.

[35] J. Wolf, F. Cruciani, A. El Labban, P. M. Beaujuge, Chem. Mater. 2015, 27, 4184.

[36] J. Warnan, A. El Labban, C. Cabanetos, E. T. Hoke, P. K. Shukla, C. Risko, J. L. Bredas, M. D. McGehee, P. M. Beaujuge, Chem. Mater. 2014, 26, 2299.

[37] L. J. Huo, S. Q. Zhang, X. Guo, F. Xu, Y. F. Li, J. H. Hou, Angew. Chem. Int. Ed. 2011, $50,9697$. 


\section{WILEY-VCH}

[38] R. M. Duan, L. Ye, X. Guo, Y. Huang, P. Wang, S. Q. Zhang, J. P. Zhang, L. J. Huo, J. H. Hou, Macromolecules 2012, 45, 3032.

[39] S. Q. Zhang, L. Ye, Q. Wang, Z. J. Li, X. Guo, L. J. Huo, H. L. Fan, J. H. Hou, J. Phys. Chem. C 2013, 117, 9550.

[40] L. T. Dou, J. Gao, E. Richard, J. B. You, C. C. Chen, K. C. Cha, Y. J. He, G. Li, Y. Yang, J. Am. Chem. Soc. 2012, 134, 10071.

[41] D. Deng, Y. J. Zhang, J. Q. Zhang, Z. Y. Wang, L. Y. Zhu, J. Fang, B. Z. Xia, Z. Wang, K. Lu, W. Ma, Z. X. Wei, Nat. Commun. 2016, 7, 13740.

[42] Z. G. Wang, X. P. Xu, Z. J. Li, K. Feng, K. Li, Y. Li, Q. Peng, Adv. Electron. Mater. 2016, 2, 1600061 .

[43] X. G. Guo, N. J. Zhou, S. J. Lou, J. Smith, D. B. Tice, J. W. Hennek, R. P. Ortiz, J. T. L. Navarrete, S. Y. Li, J. Strzalka, L. X. Chen, R. P. H. Chang, A. Facchetti, T. J. Marks, Nat. Photonics 2013, 7, 825.

[44] Y. X. Li, L. Zhong, F. P. Wu, Y. Yuan, H. J. Bin, Z. Q. Jiang, Z. J. Zhang, Z. G. Zhang, Y. F. Li, L. S. Liao, Energy Environ. Sci. 2016, 9, 3429.

[45] H. Yao, R. Yu, T. J. Shin, H. Zhang, S. Zhang, B. Jang, M. A. Uddin, H. Y. Woo, J. Hou, Adv. Energy Mater. 2016, 6, 1600742.

[46] L. K. Jagadamma, M. Abdelsamie, A. El Labban, E. Aresu, G. O. N. Ndjawa, D. H. Anjum, D. Cha, P. M. Beaujuge, A. Amassian, J. Mater. Chem. A 2014, 2, 13321.

[47] K. Do, Q. Saleem, M. K. Ravva, F. Cruciani, Z. P. Kan, J. Wolf, M. R. Hansen, P. M. Beaujuge, J. L. Bredas, Adv. Mater. 2016, 28, 8197.

[48] S. Q. Zhang, L. Ye, J. H. Hou, Adv. Energy Mater. 2016, 6, 1502529.

[49] Y. H. Liu, J. B. Zhao, Z. K. Li, C. Mu, W. Ma, H. W. Hu, K. Jiang, H. R. Lin, H. Ade, H. Yan, Nat. Commun. 2014, 5, 5293.

[50] W. Chen, Q. Zhang, J. Mater. Chem. C 2017, 5, 1275. 


\section{WILEY-VCH}

[51] C. Piliego, T. W. Holcombe, J. D. Douglas, C. H. Woo, P. M. Beaujuge, J. M. J. Frechet, J. Am. Chem. Soc. 2010, 132, 7595.

[52] Y. P. Zou, A. Najari, P. Berrouard, S. Beaupre, B. R. Aich, Y. Tao, M. Leclerc, J. Am. Chem. Soc. 2010, 132, 5330.

[53] Y. Y. Liang, Z. Xu, J. B. Xia, S. T. Tsai, Y. Wu, G. Li, C. Ray, L. P. Yu, Adv. Mater. 2010, 22, E135.

[54] S. Q. Zhang, L. Ye, W. C. Zhao, D. L. Liu, H. F. Yao, J. H. Hou, Macromolecules 2014, $47,4653$.

[55] L. Ye, S. Q. Zhang, W. C. Zhao, H. F. Yao, J. H. Hou, Chem. Mater. 2014, 26, 3603.

[56] J. Peet, J. Y. Kim, N. E. Coates, W. L. Ma, D. Moses, A. J. Heeger, G. C. Bazan, Nat. Mater. 2007, 6, 497.

[57] J. K. Lee, W. L. Ma, C. J. Brabec, J. Yuen, J. S. Moon, J. Y. Kim, K. Lee, G. C. Bazan, A. J. Heeger, J. Am. Chem. Soc. 2008, 130, 3619.

[58] K. Schmidt, C. J. Tassone, J. R. Niskala, A. T. Yiu, O. P. Lee, T. M. Weiss, C. Wang, J. M. J. Frechet, P. M. Beaujuge, M. F. Toney, Adv. Mater. 2014, 26, 300.

[59] V. D. Mihailetchi, L. J. A. Koster, J. C. Hummelen, P. W. M. Blom, Phys. Rev. Lett. 2004, 93, 216601.

[60] M. Lenes, M. Morana, C. J. Brabec, P. W. M. Blom, Adv. Funct. Mater. 2009, 19, 1106.

[61] D. Mori, H. Benten, I. Okada, H. Ohkita, S. Ito, Energy Environ. Sci. 2014, 7, 2939.

[62] S. R. Cowan, A. Roy, A. J. Heeger, Phys. Rev. B 2010, 82, 245207.

[63] C. G. Shuttle, B. O'Regan, A. M. Ballantyne, J. Nelson, D. D. C. Bradley, J. R. Durrant, Phys. Rev. B 2008, 78, 113201.

[64] C. G. Shuttle, A. Maurano, R. Hamilton, B. O'Regan, J. C. de Mello, J. R. Durrant, Appl. Phys. Lett. 2008, 93, 183501. 


\section{WILEY-VCH}

[65] S. M. Tuladhar, M. Azzouzi, F. Delval, J. Yao, A. A. Y. Guilbert, T. Kirchartz, N. F. Montcada, R. Dominguez, F. Langa, E. Palomares, J. Nelson, ACS Energy Lett. 2016, 1, 302.

[66] J. Z. Yao, T. Kirchartz, M. S. Vezie, M. A. Faist, W. Gong, Z. C. He, H. B. Wu, J. Troughton, T. Watson, D. Bryant, J. Nelson, Phys. Rev. Appl. 2015, 4, 014020.

[67] J. Liu, S. Chen, D. Qian, B. Gautam, G. Yang, J. Zhao, J. Bergqvist, F. Zhang, W. Ma, H. Ade, O. Inganäs, K. Gundogdu, F. Gao, H. Yan, Nat. Energy 2016, 1, 16089.

[68] J. A. Bartelt, J. D. Douglas, W. R. Mateker, A. El Labban, C. J. Tassone, M. F. Toney, J. M. J. Frechet, P. M. Beaujuge, M. D. McGehee, Adv. Energy Mater. 2014, 4, 1301733.

[69] B. J. T. de Villers, R. C. I. MacKenzie, J. J. Jasieniak, N. D. Treat, M. L. Chabinyc, Adv. Energy Mater. 2014, 4, 1301290.

[70] T. Wang, A. J. Pearson, D. G. Lidzey, J. Mater. Chem. C 2013, 1, 7266.

[71] P. A. Staniec, A. J. Parnell, A. D. F. Dunbar, H. N. Yi, A. J. Pearson, T. Wang, P. E. Hopkinson, C. Kinane, R. M. Dalgliesh, A. M. Donald, A. J. Ryan, A. Iraqi, R. A. L. Jones, D. G. Lidzey, Adv. Energy Mater. 2011, 1, 499.

[72] A. C. Mayer, M. F. Toney, S. R. Scully, J. Rivnay, C. J. Brabec, M. Scharber, M. Koppe, M. Heeney, I. McCulloch, M. D. McGehee, Adv. Funct. Mater. 2009, 19, 1173.

[73] M. Causa, J. De Jonghe-Risse, M. Scarongella, J. C. Brauer, E. Buchaca-Domingo, J. E. Moser, N. Stingelin, N. Banerji, Nat. Commun. 2016, 7, 12556.

[74] K. R. Graham, C. Cabanetos, J. P. Jahnke, M. N. Idso, A. El Labban, G. O. N. Ndjawa, T. Heumueller, K. Vandewal, A. Salleo, B. F. Chmelka, A. Amassian, P. M. Beaujuge, M. D. McGehee, J. Am. Chem. Soc. 2014, 136, 9608.

[75] A. Armin, G. Juska, M. Ullah, M. Velusamy, P. L. Burn, P. Meredith, A. Pivrikas, Adv. Energy Mater. 2014, 4, 1300954.

[76] G. Juska, N. Nekrasas, K. Genevicius, J. Non-Cryst. Solids 2012, 358, 748. 


\section{Polymer Main-Chain Substitution Effects on the Efficiency of}

\section{Nonfullerene BHJ Solar Cells}

Yuliar Firdaus,,$^{\dagger \neq}$ Luna P. Maffei, ${ }^{\dagger, \neq}$ Federico Cruciani,${ }^{\dagger}$ Michael A. Muller, ${ }^{\dagger}$ Shengjian Liu, ${ }^{\dagger}$ Sergei Lopatin, ${ }^{\S}$ Nimer Wehbe,,$^{\S}$ Guy O. Ngongang Ndjawa, ${ }^{\dagger}$ Aram Amassian, ${ }^{\dagger}$ Frederic Laquai, ${ }^{\dagger}$ and Pierre M. Beaujuge ${ }^{*, t}$

Keywords: polymer solar cells, nonfullerene acceptor, benzo[1,2-b:4,5-b ']dithiophene (BDT), organic photovoltaics, 3,4-difluorothiophene, ITIC

\section{Table of contents entry:}

Swapping main-chain substituents in a set of analogous wide-bandgap polymer donors is shown to result in gradual bulk-heterojunction (BHJ) device performance improvements when the polymers are combined with the nonfullerene acceptor ITIC. Our systematic device characterizations indicate that the gradual improvements result from better charge generation, collection, and reduced geminate and bimolecular recombination, leading to polymernonfullerene BHJ solar cells with power conversion efficiencies as high as $9.8 \%$.
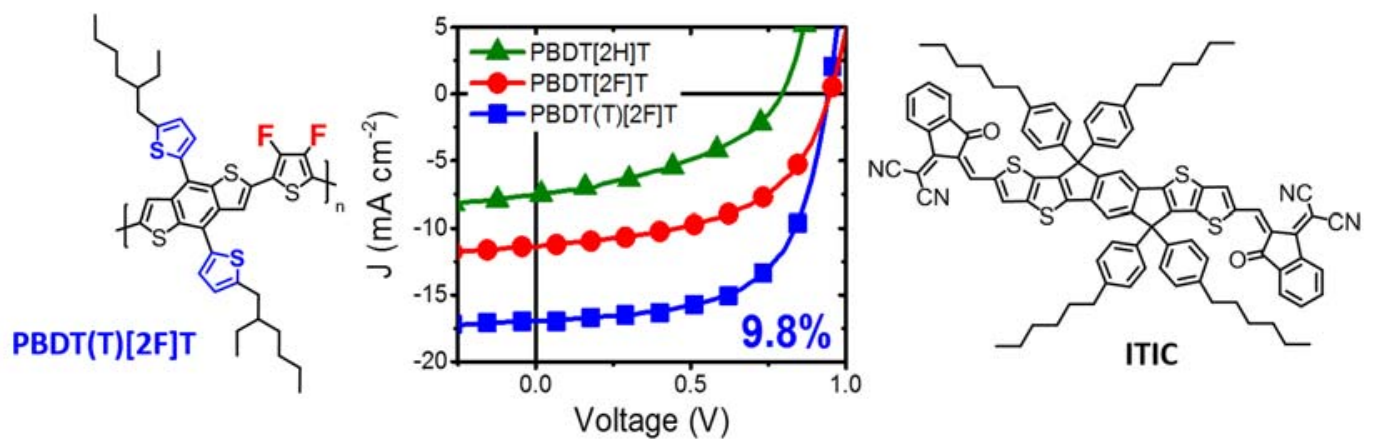